УДК 622.648.001.24:622.7.004.8

РАСЧЕТ ПАРАМЕТРОВ И РЕЖИМОВ ГИДРОТРАНСПОРТИРОВАНИЯ ПРИ РАЗРАБОТКЕ ТЕХНОГЕННЫХ МЕСТОРОЖДЕНИЙ В ХРАНИЛИЩАХ ОТХОДОВ ОБОГАЩЕНИЯ

${ }^{1}$ Семененко Е.В., ${ }^{1}$ Медведева О.А., ${ }^{1}$ Киричко С.Н., ${ }^{2}$ Никифорова Н.А.

${ }^{1}$ Институт геотехнической механики им. Н.С. Полякова НАН Украины, ${ }^{2}$ Национальная металлургическая академия Украинь МОН Украинь

РОЗРАХУНОК ПАРАМЕТРІВ ТА РЕЖИМІВ ГІДРОТРАНСПОРТУВАННЯ ПРИ РОЗРОБЦІ ТЕХНОГЕННИХ РОДОВИЩ В СХОВИЩАХ

ВІДХОДІВ ЗБАГАЧЕННЯ

${ }^{1}$ Семененко Є.В., 'Медведєва О.О., ${ }^{1}$ Киричко С.М., ${ }^{2}$ Нікіфророва Н.А.

${ }^{1}$ Інститут геотехнічної механіки ім. М.С. Полякова НАН України, ${ }^{2}$ Національна металургійна Украӥни академія МОН України

\title{
THE CALCULATION OF PARAMETERS AND MODES OF HYDROTRANSPORT IN THE DEVELOPMENT OF MAN-MADE DEPOSITS \\ IN THE STORAGE OF WASTE PRODUCTS \\ ${ }^{1}$ Semenenko Ye.V., ' ${ }^{1}$ Medvedeva O.O., ${ }^{1}$ KyrychkoS.M., ${ }^{2}$ Nikiforova N.A.
}

${ }^{1}$ Institute of Geotechnical Mechanics named by N. Poljakov NAS of Ukraine, ${ }^{2}$ National Metallurgical Academy of Ukraine MES of Ukraine

Аннотация. В статье рассмотрены технологии пульпоприготовления и приведены их характеристики и особенности. Исследованы технологические процессы пульпоприготовления, на основании которых выбран наиболее перспективный способ для применения на отечественных горно-обогатительных комбинатах. Обоснованы размеры узла пульпоприготовления, которые ограничиваются величиной верхнего гребня дамбы, и определяются требуемой производительностью гидросмеси. Объем техногенной россыпи при расчетах в работе определяется, исходя их принятого добычного оборудования, и принимается постоянным, а объемный расход воды, подаваемой из прудка, устанавливается с учетом расходно-напорных характеристик системы водоснабжения, который может регулироваться при переходе от карты к карте либо переходе на новый ярус хранилища. Кроме того, в работе оценены значения удельного расхода воды на пульпообразование, при которых изменяются тип гидросмеси и режим ее течения по магистрали. Получен критический диаметр трубопровода по заданным параметрам добычного комплекса и принятой системы пульпоприготовления. По результатам проведенных исследований обоснованы параметры технологий гидромеханизации для разработки техногенных месторождений, сформированных в хранилищах отходов обогащения. По результатам проведенных исследований и полученных зависимостей можно разработать рекомендации по обоснованию параметров процессов восстановления аккумулирующей способности прудка с использованием средств гидромеханизации. Результаты, полученные при выполнении работы, предназначены для использования проектными организациями и горно-металлургическими предприятиями для обеспечения производственных мощностей и продления срока эксплуатации хранилищ отходов обогащения, путем восстановления их аккумулирующей способности.

Ключевые слова: гидротранспорт, техногенные месторождения, гидросмесь, расходно-напорные характеристики, высокая концентрация.

\section{Введение.}

Технологии пульпоприготовления, которые получили распространение при гидромеханизации открытых горных работ, и применимы в условиях попутной добычи техногенных россыпей на искусственных хранилищах отходов (ХО), можно разделить на группы: струйные, бункерные, эжекторные. 
ISSN 1607-4556 (Print), ISSN 2309-6004 (Online) Геотехнічна механіка. 2018. №142

Особенностью струйных технологий пульпоприготовления является использование свободных струй жидкости для смешивания твердой и жидкой фазы на открытом пространстве, откуда образованная пульпа поступает в зумпф, а далее после корректировки концентрации, попадает в трубопровод. К технологиям такого типа относят варшгрейдеры, гидромониторные площадки, смесительные канавы. Однако, они требуют предварительного аккумулирования некоторого запаса твердого материала, который может потом пополняться во время работы. Для этих технологий свойственно применение гидромониторов для создания струй и подачи воды в зумпф для корректировки концентрации пульпы, а также бутар для смешивания фаз.

Бункерные технологии пульпоприготовления характеризуются организацией процесса смешивания жидкой и твердой фаз пульпы в некоторой емкости бункере или зумпфе, из которой готовая пульпа поступает в трубопровод. В этом случае обе фазы обычно подаются одновременно или одна из них периодически, обычно это твердая фаза. К технологиям такого типа относят струйные зумпфы, обычные зумпфы, зумпфы-мешалки, смесительные воронки, воронки с тангенциальной подачей жидкости. Управление концентрацией готовой пульпы обеспечивается выбором объемных расходов фаз, а равномерность перемешивания способами их подачи. Так известны несколько конструкций струйных зумпфов, которые обеспечивают стабильное значение концентрации пульпы.

Эжекторные технологии пульпоприготовления основаны на смешивании потоков двух фаз в трубопроводе, при этом может использоваться как эффект эжектирования твердой фазы жидкой, так и попадание твердого материала в поток под действием силы тяжести. В некоторых случаях используются установки оборудованные шнеками для подачи твердых частиц или для смешивания фаз с последующей подачей в трубопровод готовой гидросмеси.

При выборе технологии и технических средств пульпоприготовления, позволяющих осуществлять пульпообразование в заданных объемах на текущей дамбе обвалования.

Цель работы заключается в установлении и обосновании параметров и режимов гидротранспортирования при разработке техногенных россыпей, которые сформировались в процессе складирования отходов обогащения в хранилищах.

Прежде всего, необходимо учитывать ограничения габаритов узла пульпоприготовления, которые сдерживаются размером верхнего гребня дамбы. В некоторых случаях эти ограничения можно расширить, использовав под узел пульпообразования придамбовый участок пляжа, на котором в результате этого не будет проводиться добыча техногенной россыпи.

В значительной степени размеры узла пульпоприготовления, независимо от выбранной технологии, будут определяться требуемой производительностью по гидросмеси:

$$
Q=Q_{S}+v Q_{S}+Q_{w},
$$


где $Q$ - объемный расход готовой гидросмеси; $Q_{S}$ - объемный расход техногенной россыпи; $v$ - влажность техногенной россыпи; $Q_{w}$ - объемный расход воды подаваемой из пруда отстойника.

В рассматриваемом случае, принимая предположения модели процесса пульпообразования, предложенные в [2 - 5], можно записать следующие формулы для определения параметров готовой пульпы:

$$
\begin{array}{ll}
Q=Q_{S}(1+v+q), & G=\rho_{S} Q_{S}\left(1+\frac{v+q}{A r+1}\right), \quad C_{V}=\frac{1}{1+v+q}, \\
C=\frac{1}{1+\frac{v+q}{A r+1}}, & \rho=1+\frac{A r}{1+v+q}, \quad q=\frac{Q_{w}}{Q_{S}}, \quad A r=\frac{\rho_{S}-\rho_{W}}{\rho_{W}},
\end{array}
$$

где $G$ - грузопоток; $C$ - массовая концентрация пульпы; $C_{V}$ - объемная концентрация пульпы; $A r$ - параметр Архимеда транспортируемого материала; $\rho_{S}$ - средневзвешенная плотность частиц транспортируемого материала; $\rho_{W}-$ плотность воды; $q$ - удельный расход воды на пульпообразование [2 - 7].

Если величина влажности добываемой техногенной россыпи пренебрежимо мала, по сравнению с удельным расходом воды на пульпообразование, то вместо вышеприведенных формул можно использовать следующие зависимости:

$$
Q=Q_{S}(1+q), G=\rho_{S} Q_{S}\left(1+\frac{q}{A r+1}\right), C_{V}=\frac{1}{1+q}, C=\frac{1}{1+\frac{q}{A r+1}}, \rho=1+\frac{A r}{1+q} .
$$

Определяемый по формулам (1) и (3) расход пульпы является характеристикой узла пульпориготовления и не учитывает режим течения суспензии, который зависит от диаметра трубопровода (табл. 1), а также расходно-напорную характеристику магистрали, которая при полученных значениях концентрации может обеспечить некоторый расход, больший или меньший рассчитанного.

Таблица 1 - Классификация режимов течения пульп различной концентрации

\begin{tabular}{|c|c|c|}
\hline \multirow{2}{*}{$\begin{array}{c}\text { Классификация пульп } \\
\text { по концентрации }\end{array}$} & \multicolumn{2}{|c|}{ Классификация режимов течения пульп } \\
\cline { 1 - 3 } Низкая концентрация & Гетерогенная жидкость & Однородная жидкость \\
\hline Средняя концентрация & $V<1,25 V_{k p}$ & $V \geq 1,25 V_{k p}$ \\
\hline Высокая концентрация & Стержневой режим & Турбулентный режим \\
\hline
\end{tabular}

Примечание: В таблице использованы следующие обозначения: $V$ - средняя расходная скорость течения пульпы; $V_{k p}$ - критическая скорость гидротранспортирования [1 - 6].

В формулах (1) - (3) величина $Q_{S}$ определяется выбранным добычным оборудованием и в рамках данной задачи является константой, а величина $Q_{w}$ оп- 
ISSN 1607-4556 (Print), ISSN 2309-6004 (Online) Геотехнічна механіка. 2018. №142

ределяется расходно-напорными характеристиками системы водоснабжения и может изменяться при переходе от карты к карте, а также при переходе на новый ярус намыва. Из формул (1) - (3) видно, что при изменениях величины $Q_{w}$ будут меняться не только расход пульпы, но и ее концентрация, в результате чего могут измениться режим работы и тип поставляемой на обогатительную фабрику суспензии.

Таким образом, необходимо оценить значения удельного расхода воды на пульпообразование, при которых будут изменяться тип гидросмеси и режим ее течения по магистрали.

Соответствующие ограничения удельного расхода воды на пульпообразование, при которых будут изменяться тип гидросмеси (табл. 2). Рассматривая совместно формулу для $C$ из (2) и зависимости получим:

$$
C_{m}=0,2 \frac{A r+1}{A r}, \quad C_{P}=\frac{1}{1+\frac{2,33}{A r+1}}, \quad C_{L}=\frac{1+A r}{\frac{3,33}{2-P_{0.1}}+A r},
$$

где $C_{m}$ - граничное значение массовой концентрации для пульп низкой концентрации [1, 7 - 9]; $C_{P}$ - граничное значение массовой концентрации для пульп средней концентрации [9]; $C_{L}$ - предельно возможная массовая концентрация гидросмеси, соответствующая плотной упаковке твердых частиц [5 $10] ; P_{0.1}$ - доля в транспортируемом материале частиц диаметром менее 0,1 мм [11 $14]$.

Таблица 2 - Ограничения значений $q$ для пульп разного типа

\begin{tabular}{|c|c|c|}
\hline $\begin{array}{c}\text { Классификация пульп } \\
\text { по концентрации }\end{array}$ & $\begin{array}{c}\text { Ограничения } \\
\text { величины } q\end{array}$ & $\begin{array}{c}\text { Граничное значение } \\
\text { параметра } q\end{array}$ \\
\hline Низкая концентрация & $q_{m}<q$ & $q_{m}=4 A r-1-v$ \\
\hline Средняя концентрация & $q_{P}<q<q_{m}$ & $q_{P}=3,33-1-v$ \\
\hline Высокая концентрация & $q_{L}<q<q_{P}$ & $q_{L}=\frac{3,33}{2-P_{0.1}}-1-v$ \\
\hline
\end{tabular}

При этом для каждого типа гидросмеси будут использоваться отдельные зависимости для расчета критической скорости гидротранспортирования и формулы, которые предопределяют различные зависимости для выбора диаметра трубопровода [1]. Диаметр трубопровода, обеспечивающего подачу добытой техногенной россыпи на обогатительное производство, выбирается из условия, что при заданном расходе пульпы будет обеспечиваться сверхкритическая скорость течения 
ISSN 1607-4556 (Print), ISSN 2309-6004 (Online) Геотехнічна механіка. 2018. №142

$$
Q=K V_{k p} \frac{\pi D^{2}}{4}
$$

где $D$ - диаметр трубопровода; $K$ - параметр гидротранспортирования, $K>1$ $[2,4]$.

Следует отметить, что для пульп низкой концентрации критическая скорость гидротранспортирования с учетом зависимости относительной плотности пульпы от показателей процесса пульпообразования (2), определяется по формуле

$$
V_{k p}=15 \sqrt[3]{D} \sqrt[4]{w}\left(0,6+\frac{A r}{1+v+q}\right)
$$

с учетом этого, а также зависимостей (1), величина критического диаметра трубопровода будет

$$
D_{k p}=\left(\frac{A r Q_{S}}{4,24 K \sqrt[4]{w}}\right)^{\frac{3}{7}}\left(\frac{x^{2}}{x+1}\right)^{\frac{3}{7}}, \quad x=\frac{0,6}{A r}(1+v+q)
$$

где $D_{k p}$ - критический диаметр трубопровода; $x$ - величина, характеризующая зависимость критического диаметра от параметров процесса пульпообразования.

Величина критического диаметра ограничивается значениями диаметров трубопровода, из существующего сортамента, для которых режим течения гидросмеси будет сверхкритическим. Из формулы (5) видно, что величина критического диаметра определяется произведением двух сомножителей - первый из них учитывает влияние производительности добычного комплекса, а второй зависимость от параметров системы пульпоприготовления. Для исследования этой зависимости запишем формулу (5) в следующем виде:

$$
\delta=\left(\frac{x^{2}}{x+1}\right)^{\frac{3}{7}}, \delta=\frac{D_{k p}}{D_{*}}, \quad D_{*}=\left(\frac{A r Q_{S}}{4,24 K \sqrt[4]{w}}\right)^{\frac{3}{7}}
$$

где $\delta$ - относительный критический диаметр; $D_{*}-$ фиктивный технологический диаметр трубопровода $[2,15]$.

Исследование зависимости (6) методами вычислительной математики позволило предложить для рационального диапазона изменений параметра пульпообразования следующую аппроксимацию

$$
\delta=0,712 x^{0,62}
$$


ISSN 1607-4556 (Print), ISSN 2309-6004 (Online) Геотехнічна механіка. 2018. №142

При этом следует, что при значениях параметра пульпоприготовления больше пяти, то есть для пульп низкой концентрации (см. табл. 2), справедливы следующие приближенные формулы:

$$
x=q \frac{0,6}{A r}, \quad \delta=0,64\left(\frac{q}{A r}\right)^{0,62} .
$$

По заданным параметрам добычного комплекса и системы пульпоприготовления с использованием формул (6) и (7) определяют критический диаметр трубопровода, по которому из сортамента труб выбирают ближайший меньший диаметр. После этого рассчитывают плотность и концентрацию гидросмеси, критическую скорость гидротранспортирования, а затем, зафиксировав значения этих величин, определяют гидравлический уклон и возможную подачу пульпы. Полученное значение подачи сравнивают со значением подачи пульпы, вычисленным по формуле (1). Если разница между полученными значениями удовлетворяет точность расчетов, то вычисления заканчивают, если нет, то изменяют значение величины $q$ и повторяют расчет заново.

Такой алгоритм не удобен для практических расчетов в производственных условиях, поскольку предполагает итерационный процесс вычисления, и сходимость вычислительного процесса зависит от наличия тех или иных труб в сортаменте. Упростить использование формул (6) и (7) можно в том случае, когда расчетные значения критического диаметра оказались в диапазоне используемых труб. Тогда можно получить зависимость величины $q$ от относительного критического диаметра. Выражение (6) после замены переменной преобразуется к квадратному уравнению, решение которого имеет следующий вид

$$
q=b D_{k p}^{\frac{7}{3}}[\sqrt{1+B}-1]-(1+v), \quad B=\frac{0,943 \operatorname{Ar} Q_{S}}{K \sqrt[4]{w} D_{k p}^{\frac{7}{3}}}, \quad b=\frac{K \sqrt[4]{w}}{0,823 Q_{S}},
$$

а выражение (7) преобразуется в формулу:

$$
q=6,829 A r^{0,922} b^{0,691} D_{k p}^{1,613}-(1+v)
$$

Подставив зависимость (8) в формулы (1) - (3) получим выражения для определения параметров пульпы подаваемой из проектируемого узла пульпориготовления

$$
Q=a b D_{k p}^{\frac{7}{3}}, \quad Q_{w}=a b D_{k p}^{\frac{7}{3}}-(1+v) Q_{S}, \quad \rho=1+\frac{B}{a}, \quad C=\frac{A r+1}{A r+a b D_{k p}^{\frac{7}{3}}}, \quad a=\sqrt{1+B}-1
$$


ISSN 1607-4556 (Print), ISSN 2309-6004 (Online) Геотехнічна механіка. 2018. №142

В полученных формулах в качестве критического диаметра используется диаметр трубы существующей в сортаменте округленный к ближайшему целому числу.

Для пульп средней концентрации величина критической скорости несколько снижается по сравнению со значением, которое оно достигает при концентрации $C_{m}$, и для расчетов, с учетом зависимости относительной плотности пульпы от показателей процесса пульпообразования (3), рекомендовано использовать следующую формулу [15 - 20]:

$$
V_{k p}=12,8 \sqrt[3]{D} \sqrt[4]{w} \sqrt[3]{1+\frac{1+v+q}{A r}}
$$

с учетом этого, а также зависимости (1), вместо вышеприведенных формул для расчета критического диаметра трубопровода рекомендуется использовать:

$$
\delta=\left(\frac{x^{3}}{x+1}\right)^{\frac{1}{7}}, \quad x=\frac{1+v+q}{A r}, \quad D_{*}=\left(\frac{0,0995 \operatorname{Ar} Q_{S}}{K \sqrt[4]{w}}\right)^{\frac{3}{7}}
$$

Вид функции аппроксимации и упрощенных формул сохранится, изменятся только входящие в них коэффициенты:

$$
\delta=0,901 x^{0,33}, \quad x=\frac{q}{A r}, \quad \delta=0,901\left(\frac{q}{A r}\right)^{0,33} .
$$

Для случая пульп средней концентрации формул вида (9) и (10) не получается, так как в отличие от формулы (6) при разрешении зависимости (11) относительно $x$ от $\delta$ получается кубическое уравнение, вид решения которого определяется знаком дискриминанта:

$$
x= \begin{cases}\sqrt[3]{\frac{\delta^{7}}{2}}\left[\sqrt[3]{1+\sqrt{1-\frac{4 \delta^{7}}{27}}}+\sqrt[3]{1-\sqrt{1-\frac{4 \delta^{7}}{27}}}\right], & \delta^{7}<\frac{27}{4} \\ \sqrt{\frac{4 \delta^{7}}{3}} \cos \left[\frac{1}{3} \arccos \left(\sqrt{\frac{27}{4 \delta^{7}}}\right)\right], & \delta^{7} \geq \frac{27}{4},\end{cases}
$$

а выражение для удельного расхода воды на пульпообразование преобразуется в формулу

$$
q=1,372 A r \delta^{3,03} .
$$

Диаметр трубопровода рассматриваемых гидротранспортных установок вы- 
бирают из сортамента имеющихся в наличии труб по величине критического диаметра трубопровода, а также, исходя из способности магистрали, с таким диаметром обеспечить заданный расход с текущего яруса намыва, то есть фактически при заданной длине и перепаде геодезических высот магистрали. Для этого необходимо построить РНХ магистрали рассматриваемой гидротранспортной установки, вычислить ее параметры для выбранного диаметра, найти подачу пульпы, при которой потери напора будут равны перепаду геодезических высот, с учетом относительной плотности пульпы, и сравнить это значение с требуемым расходом пульпы.

Используя для определения параметра режима гидротранспортирования формулу

$$
K=\sqrt[3]{\frac{1,2 \sigma}{\rho-1} \cos ^{2} \alpha},
$$

наперед задаемся сверхкритическим режимом гидротранспортирования

$$
1 \leq K \leq 2,
$$

что позволяет свободно выбрать из сортамента диаметр трубы, так как запас по скорости, обусловленный режимом однородной жидкости во много превышает запас по критической скорости, обусловленный несовпадением стандартных диаметров труб и их критических значений.

Таким образом, подставив выражения для критической скорости гидротранспортирования и $K$ в (4), проведя соответствующие преобразования, нетрудно получить формулу для определения диаметра трубопровода, обеспечивающего течение гидросмеси в режиме однородной жидкости:

$$
D=\left(\frac{Q}{\sqrt[4]{w}}\right)^{\frac{3}{7}} \frac{0,34 U}{\sqrt[7]{\cos ^{2} \alpha}}, \quad U=\sqrt[7]{\frac{\rho-1}{\rho^{1,5}(1+150 d)-1}} \frac{1}{(\rho-0,4)^{\frac{3}{7}}}, d=\frac{d_{c p}}{D},
$$

где $d$ - относительная крупность транспортируемых частиц; $U$ - величина, учитывающая зависимость диаметра трубопровода от относительной плотности гидросмеси, а также от относительной крупности транспортируемых частиц (рис. 1).

Из рис. 1 видно, что величина $U$ слабо изменяется в рассматриваемом диапазоне относительной плотности пульпы, и ее значение в основном определяется величиной относительной крупности транспортируемого материала. Численный анализ показывает, что данную зависимость с инженерной точностью можно аппроксимировать следующей функцией:

$$
U=0.654\left(\frac{D}{d_{c p}}\right)^{0.046}
$$


ISSN 1607-4556 (Print), ISSN 2309-6004 (Online) Геотехнічна механіка. 2018. №142

с учетом чего выражение для расчета диаметра трубопровода будет

$$
D=\frac{0,207}{d_{c p}^{0,048} \cos ^{0,3} \alpha}\left(\frac{Q}{\sqrt[4]{w}}\right)^{0,45}
$$

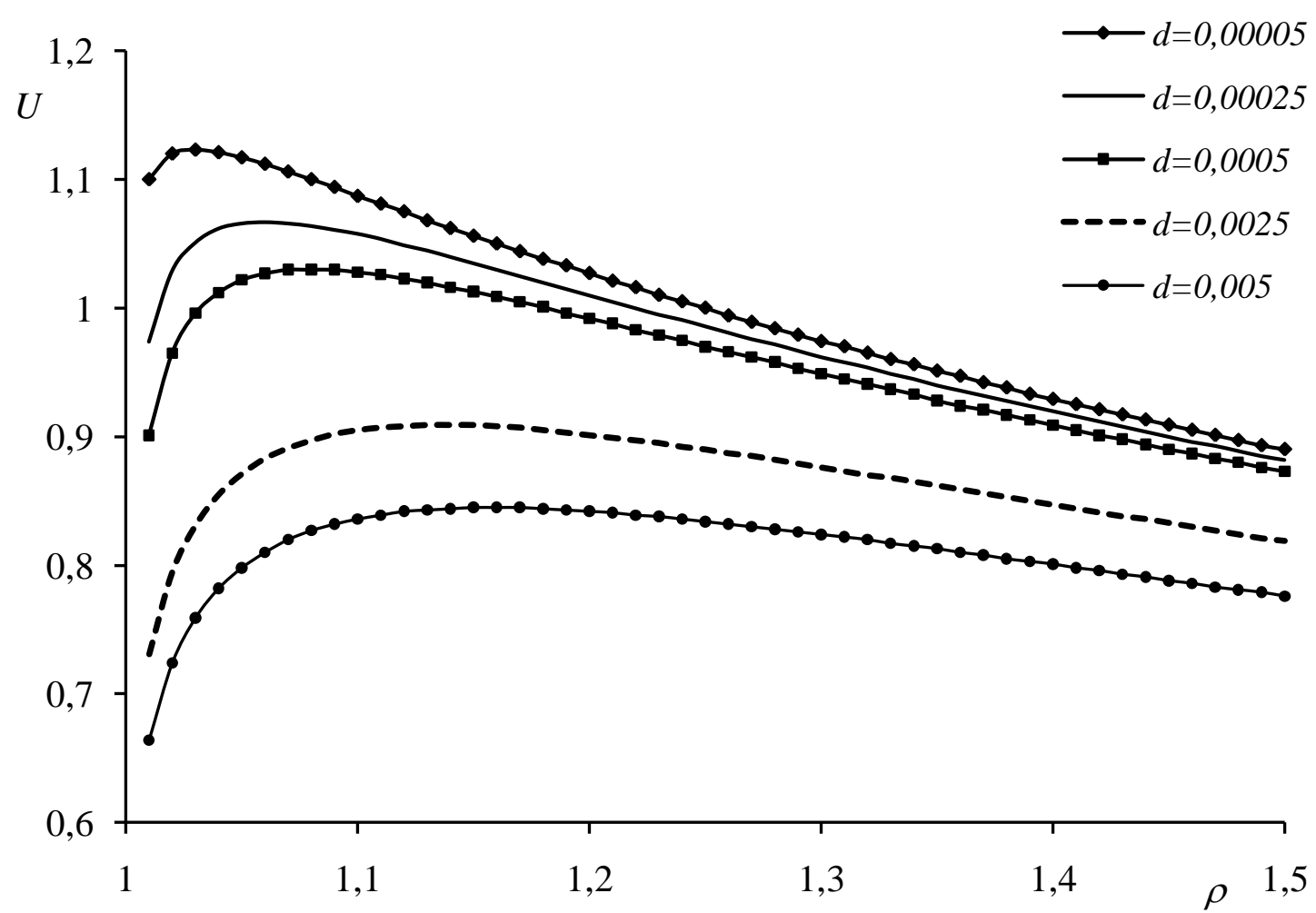

Рисунок 1 - Зависимость величины $U$ от относительной плотности гидросмеси при различных значениях относительной крупности транспортируемых частиц

Подставив выражение (7) в формулу (18) и после преобразований, получим уравнение для определения величины $q$ при течении пульпы в режиме однородной жидкости

$$
q=\frac{D^{2,2} d_{c p}^{0,107} \sqrt[4]{w}}{0,03 Q_{S}} \cos ^{0,67} \alpha-(1+v)
$$

Подставив зависимость (18) в формулы (1) и (2) получим выражения для определения параметров пульпы подаваемой из проектируемого узла пульпориготовления в режиме однородной жидкости.

Подставляя в уравнение для расчета РНХ магистрали формулу (18) и приравнивая его к нулю, после несложных преобразований получим выражение для определения возможного расхода пульпы через магистраль в режиме однородной жидкости: 


$$
\begin{aligned}
& Q=\left(w^{0,113} d_{c p}^{0,048} \frac{\cos ^{0,3} \alpha}{0,207}\right)^{m_{1}} \frac{2^{m_{2}}}{\pi^{m_{3}}}\left(\frac{k_{z} N v_{w}^{p}}{g} \frac{L_{0}+n[\beta+m] h}{Z_{0}+n h}\right)^{m_{4}}, \\
& m_{1}=\frac{5-p}{m_{4}}, m_{2}=2 \frac{1,5-p}{m_{4}}, m_{3}=\frac{2-p}{m_{4}}, m_{4}=\frac{p+0,455}{1,82} .
\end{aligned}
$$

Подставив выражения (1) в формулу (19) и проведя преобразования, получим уравнение для определения величины $q$ при течении пульпы в режиме однородной жидкости с учетом РНХ магистрали.

\section{Выводы.}

По заданным параметрам добычного комплекса и системы пульпоприготовления определяют критический диаметр трубопровода, по которому из сортамента труб выбирают ближайший меньший диаметр. После этого рассчитывают плотность и концентрацию гидросмеси, начальное касательное напряжение и структурную вязкость суспензии, а затем, зафиксировав значения этих величин, определяют возможную подачу пульпы. Полученное значение подачи сравнивают с регламентированным значением подачи пульпы. Если разница между полученными значениями удовлетворяет точность расчетов, то вычисления заканчивают, если нет, то изменяют значение величины $q$ и повторяют расчет заново. С использованием полученных зависимостей могут быть разработаны рекомендации по обоснованию параметров процессов восстановления аккумулирующей способности прудка с использованием средств гидромеханизации.

\section{СПИСОК ЛИТЕРАТУРЫ}

1. Семененко Е.В. Научные основы технологий гидромеханизации открытой разработки титан-цирконовых россыпей. Киев: Наукова думка, 2011. 232 с.

2. Трубопроводный гидротранспорт твердых сыпучих материалов / Махарадзе Л.И., Гочиташвили Т.Ш., Криль С.И. и др. - Тбилиси: Мецниереба, 2006. 350 с.

3. Обоснование параметров и режимов работы систем гидротранспорта горных предприятий / Баранов Ю.Д., Блюсс Б.А., Семененко Е.В. и др. - Днепропетровск: «Новая идеология», 2006. 416 с.

4. Гуменик И.Л., Сокил А.М., Семененко Е.В., Шурыгин В.Д. Проблемы разработки россыпных месторождений. - Днепропетровск: Січ, 2001. 224 с.

5. Круть О.А. Водовугільне паливо. - К.: Наукова думка, 2002. 172 с.

6. Киричко С.Н., Семененко Е.В. Обоснование методики расчета гидравлического уклона при течении пульпы с концентрацией пасты / Геотехническая механика. Днепропетровск: ИГТМ НАН Украины, 2013. Вып. 110. С. 121-134.

7. Баранов Ю.Д., Шурыгин В.Д., Блюсс Б.А., Семененко Е.В. Выбор и обоснование параметров системы оборотного водоснабжения Вольногорского ГМК/ Металлургическая и горнорудная промышленность: Научн.-техн. и произв. журнал. 2006. №4. С. $100-103$.

8. Семененко Е.В., Саенко В.В. Выбор диаметра трубопровода гидротранспортного комплекса с учетом параметров транспортируемого материала. // Геотехническая механика. Днепропетровск: ИГТМ НАН Украины, 1999. Вып. 12. С. 17-21.

9. Александров В.И. Методы снижения энергозатрат при гидравлическом транспортировании смесей высокой концентрации. - Санкт-Петербург: СПГГИ (ТУ), 2000. 117 с.

10. Киричко С.Н., Ртищев А.Б., Семененко Е.В. Реологические параметры высококонцентрированных отходов обогащения ЦГОКа / Форум гірників - 2014: Мат. міжн. конф., жовтень 2014 р. Дніпропетровськ, 2014. С. 177 - 183.

11. Блюсс Б.А., Головач Н.А. Совершенствование технологий предобогащения ильменитовых руд. - Днепропетровск: Полиграфист, 1999. 126 с.

12. Блюсс Б.А., Сокил А.М., Гоман О.Г. Проблемы гравитационного обогащения титан-цирконовых песков.- Днепропетровск: Полиграфист, 1999. 190 с.

13. Брагін Б.Ф., Маркунтович Ф.Д., Чернецька Н.Б. Проектування споруджень і систем трубопровідного й інших видів 
транспорту. - Луганськ: Вид-во СНУ ім. В. Даля, 2004. 208 с.

14. Медведева О.А. Технологические решения по разработке техногенных месторождений ГОКов Кривбасса // Форум гірників - 2014: Мат. міжн. конф., жовтень 2014р. - Дніпропетровськ, 2014. С. 154 - 161.

15. Медведева О.А. Анализ и современное состояние хранилищ продуктов переработки минерального сырья / Збагачення корисних копалин, 2012. №51(92). С. 22 - 29.

\section{REFERENCES}

1. Semenenko, E.V. (2011), Nauchnye osnovy tekhnologiy gidromekhanizatsii otkrytoy razrabotki titan-tsirkonovykh rossypey [Scientific basis for the technology of hydromechanization of open development of titanium-zircon alluvial deposits], Naukova Dumka, Kyiv, Ukraine.

2. Makharadze, L.I., Gochitashvili, T.Sh., Krill, S.I. et.al (2006), Truboprovodnyy gidrotransport tverdykh sypuchikh materialov [Pipeline hydrotransport of solid bulk materials], Metsniereba, Tbilisi, Georgia.

3. Baranov, Yu.D., Blyuss, B.A., Semenenko, E.V. and Shurygin, V.D. (2006), Obosnovanie parametrov i rezhimov raboty sistem gidrotransporta gornykh predpriyatiy [Justification of the parameters and modes of operation of the systems of hydrotransport mining], Novaya Ideologiya, Dnipropetrovsk, Ukraine.

4. Gumenik, I.L., Sokil, A.M., Semenenko, E.V. and Shurygin, V.D. (2001), Problemy razrabotki rossypnykh mestorozhdeniy [Problems of development of placer deposits], Sich, Dnipropetrovsk, Ukraine.

5. Krut, O.A. (2002), Vodovygilne palyvo [Carbon fuel], Naukova Dumka, Kyiv, Ukraine.

6. Kyrychko, S.N., Semenenko, E.V. (2013), "Justification of the method of calculating the hydraulic slope during the flow of the pulp with the concentration of paste", Geo-Technical Mechanics, no. 110, pp. 121-134.

7. Baranov, Yu.D., E.V., Shurygin, V.D., Blyuss, B.A. et.al (2006), "Selection and justification of the parameters of the circulating water supply system of Volnogorsky MMC", Metallurgical and Mining Industry, no. 4, pp. 100-103.

8. Semenenko, E.V. and Saenko, V.V. (1999), "Selection of the diameter of the pipeline of the hydrotransport complex taking into account the parameters of the transported material", Geo-Technical Mechanics, no. 12, pp. 17-21.

9. Aleksanrov, V.I. (2000), Metody snizheniya energozatrat pri gidravlicheskom transportirovanii smesey vysokoy kontsentratsii [Methods to reduce energy consumption in the hydraulic transportation of mixtures of high concentration], SPGGI (TU), St. Petersburg, Russia.

10. Kyrychko, S.N., Rtischev, A.B. and Semenenko, E.V. (2014), "Rheological parameters of highly concentrated waste treatment plant TsGOK", Forum Girnykiv - 2014 [Miners Forum-2014], Dnipropetrovsk, Ukraine, October 2014, pp. 177 - 183.

11. Blyuss, B.A. and Golovach, N.A. (1999), Sovershenstvovanie tekhnologiy predobogashcheniya ilmenitovykh rud [Improving the pre-enrichment technology of ilmenite ores], Polygraphist, Dnipro, Ukraine.

12. Blyuss, B.A., Sokil, A.M. and Goman, O.G. (1999), Problemy gravitatsionnogo obogascheniya titan-tsirkonovykh peskov [The problems of gravitational enrichment of titanium-zircon sands], Polygraphist, Dnipro, Ukraine.

13. Bragin, B.F., Markundovich, F.D. and Chernetska, N.B. (2004), Proektuvannya sporudzhen i sistem truboprovldnogo i inshykh vydiv transportu [Design of constructions and systems of pipeline and other types of transport], View of the SNU by V. Dal, Lugansk, Ukraine.

14. Medvedeva, O.A. (2014), "Technological solutions for the development of technogenic deposits of the Krivbass mining and processing complex", Forum Girnykiv - 2014 [Miners Forum-2014], Dnipropetrovsk, Ukraine, October 2014, pp.154 - 161.

15. Medvedeva, O.A. (2012), "Analysis and state-of-the-art storage of mineral processing products", Zbagachennya korysnykh kopalyn, no. 51 (92), pp. 22-29.

\section{Об авторах}

Семененко Евгений Владимирович, доктор технических наук, старший научный сотрудник, заведующий отделом Проблем шахтных энергетических комплексов Института геотехнической механики им. Н.С. Полякова Национальной академии наук Украины (ИГТМ НАНУ), Днепр, Украина, EVSemenenko@nas.gov.ua.

Медведева Ольга Алексеевна, кандидат технических наук, старший научный сотрудник, старший научный сотрудник отдела Геодинамических систем и вибрационных технологий Института геотехнической механики им. Н.С. Полякова Национальной академии наук Украины (ИГТМ НАНУ), Днепр, Украина, medvedevaolga1702@gmail.com.

Киричко Сергей Николаевич, кандидат технических наук, научный сотрудник отдела Геодинамических систем и вибрационных технологий Института геотехнической механики им. Н.С. Полякова Национальной академии наук Украины (ИГТМ НАНУ), Днепр, Украина, skyrychko@gmail.com.

Никифорова Нина Анатольевна, кандидат технических наук, доцент Национальной металлургической академии Украины Министерства образования и науки Украины (НМетАУ), Днепр, Украина, dmeti@dmeti.dp.ua

\section{About the authors}

Semenenko Eugeniy Vladimirovich, Doctor of Technical Sciences (D.Sc), Senior Researcher, Head of Department of Mine Energy Complexes, M.S. Polyakov Institute of Geotechnical Mechanics of the National Academy of Science of Ukraine (IGTM, NASU), Dnepr, Ukraine, EVSemenenko@nas.gov.ua.

Medvedeve Olga Alekseevna, Candidate of Technical Sciences (Ph.D.), Senior Researcher, Senior Researcher in Department of Geodynamic Systems and Vibration Technologies, M.S. Polyakov Institute of Geotechnical Mechanics NAS of Ukraine (IGTM, NAS of Ukraine), Dnepr, Ukraine, medvedevaolga1702@gmail.com. 
Kyrychko Serhii Mykolaivich, Candidate of Technical Sciences (Ph.D.), Researcher in Department of Geodynamic Systems and Vibration Technologies, M.S. Polyakov Institute of Geotechnical Mechanics of the National Academy of Science of Ukraine (IGTM, NAS of Ukraine), Dnepr, Ukraine, skyrychko@gmail.com.

Nykyforova Nina Anatoliyevna, Candidate of Technical Sciences, Assistant Professor at the National Metallurgical Academy of Ukraine under the Ministry of Education and Science of Ukraine (NMetAU), Dnepr, Ukraine, dmeti@dmeti.dp.ua.

Анотація. У статті розглянуті технології пульпоприготування і наведено їх характеристики і особливості. Досліджено технологічні процеси пульпоприготування, на підставі яких обраний найбільш перспективний спосіб для застосування на вітчизняних гірничо-збагачувальних комбінатах. Обгрунтовано розміри вузла пульпоприготування, які обмежуються величиною верхнього гребеня дамби, і визначаються необхідною продуктивністю гідросуміші. Обсяг техногенного розсипу при розрахунках в роботі визначається, виходячи із прийнятого видобувного обладнання, і приймається постійним, а об'ємна витрата води, яка подається з прудка, встановлюється з урахуванням витратно-напірних характеристик системи водопостачання. При цьому вона може регулюватися при переході від карти до карти або переході на новий ярус сховища. Крім того, в роботі оцінені значення питомої витрати води на пульпоприготування, при яких змінюються тип гідросуміші і режим її течії по магістралі. Отримано критичний діаметр трубопроводу по заданих параметрах видобувного комплексу і прийнятої системи пульпоприготування. За результатами проведених досліджень обґрунтовано параметри технологій гідромеханізації для розробки техногенних родовищ, сфрормованих в сховищах відходів збагачення. За результатами проведених досліджень і отриманих залежностей можуть бути розроблені рекомендації по обірунтуванню параметрів процесів відновлення акумулюючої здатності прудка з використанням засобів гідромеханізації. Результати, які отримані під час виконання роботи, призначені для використання проектними організаціями і гірничо-металургійними підприємствами для забезпечення виробничих потужностей і продовження терміну експлуатації сховищ відходів збагачення, шляхом відновлення їх акумулюючої здатності.

Ключові слова: гідротранспорт, техногенні родовища, гідросуміш, витратно-напірні характеристики, висока концентрація.

Annotation. In the article, technologies of pulp preparation and their characteristics and features are described. The technological processes of pulp preparation were studied, and on the basis of results the most promising method was selected for use in domestic mining and processing plants. Dimensions of the pulp preparation unit, which are limited by the upper ridge of the dam, and determined by the required capacity of the slurry, are substantiated. In the calculations in this research work, volume of technogeneous placer is determined according to the adopted specification of mining equipment and is assumed constant, while volume of water flow supplied from the pond is determined with taking into account the flow-pressure characteristics of the water supply system, which can be adjusted during the transition from card to card or transition to new store tier. In addition, rates of specific water consumption for pulp formation were estimated, at which type of slurry and mode of its flow along the highway are changed. A critical diameter of the pipeline was specified for the given parameters of the mining complex and the adopted pulp preparation system. According to the results of the research, parameters of hydromechanization technologies for the development of technogeneous deposits formed in the enrichment waste storage facilities are substantiated. According to the results of the researches and the obtained dependences, it is possible to develop recommendations for substantiating parameters of the processes of restoring the accumulation ability of the spit by using hydromechanization facilities. The results obtained during the work are intended for use by design organizations and mining and metallurgical enterprises to provide sufficient production facilities and to extend life of waste storage facilities by restoring their accumulation capacity.

Keywords: hydrotransport, man-made deposits, hydrosmixture, consumption-pressure characteristics, high concentration

Стаття надійшла до редакиії 26.11.2018

Рекомендовано до друку д-ром техн. наук, проф. Блюссом Б.О. 